\title{
Patient Navigation: The Promise to Reduce Health Disparities
}

\author{
Karen M. Freund, MD, MPH \\ Women's Health Unit, Section of General Internal Medicine, Evans Department of Medicine, and Women's Health Interdisciplinary Research Center, \\ Boston University School of Medicine, Boston, MA, USA.
}

J Gen Intern Med 26(2):110-2

DOI: $10.1007 / \mathrm{s} 11606-010-1593-5$

(c) Society of General Internal Medicine 2010

$\mathrm{T}$ here is a great need for effective interventions to address health disparities for vulnerable populations, which may be defined by low education, low literacy, low income, inadequate health insurance, or minority racial / ethnic status. Many efforts have focused on the social determinants of health, resting on the notion that the magnitude of health outcome disparities affecting so many different racial and ethnic groups argues against biologic differences, but is rather due to social and cultural influences on how patients use or receive care. This implies that personalized medicine to address genetic risk alone will not eliminate health disparities, but rather systems interventions to improve access and the process of care delivery are critical to improving the health of the entire nation.

Looking specifically at cancer outcomes, lower screening rates are well described for underserved populations ${ }^{1}$. Even where screening rates are similar between racial and ethnic groups, ${ }^{2}$ differences exist in follow up rates after abnormal screening, ${ }^{3}$ resulting in differences in stage and size of tumors at diagnosis which in turn contribute to ongoing disparities ${ }^{4}$. Safety net institutions, which are less likely to have sufficient resources to track and support patients, have populations with greater barriers to completing their diagnostic or treatment care. This perfect storm of patients with limited resources to support themselves and their families when cancer is diagnosed, and resource-poor safety net institutions with limited resources to provide extra support is at the heart of many of our nation's health disparities.

This problem has become more acute with the economic downturn, where resources to safety net institutions are increasingly strained, even while the numbers of patients losing employer-based coverage grows. As an example, in Massachusetts, the two largest safety net hospitals, Boston Medical Center, and Cambridge Health Alliance have experienced huge budget gaps. This is due to both marked state reductions in their Medicaid reimbursement rates, and payment rates for insured patients from health insurance companies being sometimes two to three times lower than those provided to nearby teaching hospitals ${ }^{5-7}$. As a result, our reimbursement systems perpetuate the continued presence of fewer resources to institutions whose patient populations have few resources.

Published online December 15, 2010
Added to this disparity the advent of pay for performance, ${ }^{8}$ where institutions will receive payments based upon performance to quality benchmarks for their entire populations. While most would agree that paying for improved outcomes provides the appropriate incentives to our health care systems, it also serves to put at greater risk those institutions caring for those most in need ${ }^{9}$. Those institutions that require additional resources to provide care may lose additional resources to care systems with patient populations better able to adhere to their doctors' recommendations. How to make the playing field level for safety net institutions is not obviously clear. The notion of having a lower achievement standard to receive performance payments for safety net institutions on its face seems to codify rather than improve health disparities, and it also is based on the notion that disparities are an intractable problem.

Patient navigation is an emerging model of improving healthcare delivered to vulnerable populations, which has primarily focused on improved cancer outcomes. Patient navigation has been defined as the logistic and emotional support offered to persons through the cancer care continuum from screening, through diagnostic evaluation and cancer treatment. The goal of patient navigation is to support patients in overcoming logistical barriers to care and facilitate timely access to quality cancer care that meets cultural needs for all patients. Navigators work to address financial and insurance issues, coordinate appointments and care among multiple cancer providers, address language and health literacy needs and train patients to advocate for themselves in the health care system $^{10}$. The term "patient navigation" was coined by Dr. Harold Freeman, as a care management system to address cancer disparities. His initial demonstration project ${ }^{11}$ has been followed by studies demonstrating that additional staffing resources to providers in safety net institutions can improve intermediate outcomes of completion and timeliness of screening and diagnostic care, as a mechanism to ultimately improving health outcomes ${ }^{12-14}$.

Patient navigation shares many attributes with other care management models. Most patient navigation programs have been housed directly with the providers of health care and facilitate care through providing a liaison between patients and the health care team. A recent Centers for Medicare and Medicaid (CMS) program investigating the clinical and financial benefit of care management programs funded multiple models of care, ranging from off-site telephone-based interventions, to clinicallybased programs linked with the providers of care. Of the 15 funded programs, only two showed a benefit; both were programs with face to face as opposed to telephone-only contact, and were programs housed and organized with the providers of care ${ }^{15}$.

The two studies published in this issue of JGIM provide further support of the patient navigation model. Both programs are funded through the Avon Foundation, which has 
provided consistent support for breast cancer care to safety net programs over the past decade. The study by Phillips and colleagues ${ }^{16}$ addressed low HEDIS-measured screening mammography, and studied the impact of patient navigation through a pre-post difference in difference analysis. The $10 \%$ improvement in HEDIS rates achieved by the intervention is noteworthy in that it would allow such a safety net system to benefit from most pay for performance programs. The findings illustrate that unstable housing and incorrect contact information in their patient populations remain limitations to this patient navigation model.

Donelan and colleagues ${ }^{17}$ studied patient satisfaction with the patient navigator model of care. They compared patients from their community health center affiliates, predominantly low income, minority women, with a primarily white, educated population whose primary care was not through a safety net institution. Both populations reported similar satisfaction with care after abnormal breast cancer screening. The lack of demographic overlap between the two groups prevents multivariable or propensity adjustment to fully understand what impact the navigation model played in the results. The authors conclude that the navigated and nonnavigated groups report similar perceptions of the quality of their care. It is not clear whether this indicates that the navigated group would have been equally satisfied with their care without navigation or whether prior to navigation, the minority population would have reported a poorer experience with care that was ameliorated with navigation. Further research needs to study this issue with appropriate control populations, to understand if patient navigation is serving to benefit the quality of care in low income and minority communities. ${ }^{18,19}$

The initial reports suggest that patient navigation holds promise to address care needs to vulnerable populations, and bridge the disparities gap. Currently, however, patient navigation systems are more likely to be found and marketed in systems caring and targeting patients who are insured, employed and educated. Paradoxically, if patient navigation is an effective modality for improving care, there is a risk of it increasing rather than eliminating health disparities. Few safety net institutions have the ongoing resources to support this augmentation to care, and insurers do not reimburse this care. This is in contrast to hospitals and health care systems providing care to predominantly insured populations, where resources are present to support patient navigation services. The websites of most private cancer care centers tout the benefits of their patient navigation, and these are now seen as standards of care by some cancer care accreditation organizations including the National Accreditation Program for Breast Centers ${ }^{20}$, and the National Comprehensive Cancer Networks ${ }^{21}$. Even as patient navigation is studied to ensure appropriate care to the underserved, its major implementation has been in insured populations who already have better health outcomes. Health care reform has at its goal a transition into a care management approach, as a necessary step to improving quality and reducing cost. We will need to carefully watch that resources including patient navigation and case management are provided to safety net institutions to address the challenges that their populations face, if we hope to reduce and not increase disparities in care.
Acknowledgements: The author has received support from the Avon Foundation, Komen for the Cure Foundation, and is Principal Investigator of one of the NCI funded Patient Navigation Research Program grants U01 CA116892.

Disclaimer: Editor's note: Dr. Freund is a co-author on the paper by Phillips et al. (reference \#16).

\section{Conflicts of Interest: None Disclosed.}

Corresponding Author: Karen M. Freund, MD, MPH; Women's Health Unit, Section of General Internal Medicine, Evans Department of Medicine, and Women's Health Interdisciplinary Research Center, Boston University School of Medicine, 801 Massachusetts Avenue, Suite 470, Boston, MA 02118, USA (e-mail: Karen.Freund@bmc.org).

\section{REFERENCES}

1. Weir HK, Thun MJ, Hankey BF, Ries LAG, Howe HL, Wingo PA, Jemal A, Ward E, Anderson RN, Edwards BK. Annual report to the nation on the status of cancer, 1975-2000, featuring the uses of surveillance data for cancer prevention and control. J Natl Cancer Inst. 2003;95(17):1276-99.

2. Green EH, Freund KM, Posner MA, David MM. Pap smears rates among Haitian immigrant women in eastern Massachusetts. Public Health Rep. 2005;120:133-139.

3. Battaglia TA, Santana MC, Bak S, et al. Predictors of timely follow-up after abnormal cancer screening among women seeking care at urban community health centers. Cancer. 2010;116(4):91321.

4. Richards WA, Westcombe AM, Love SB, Littlejohns P, Ramirez AJ. Influence of delay on survival in patients with breast cancer: a systematic review. Lancet. 1999;353(9159):1119-26.

5. Krasner J. State urged to review fees to elite hospitals. The Boston Globe [Internet]. Available at: http://www.boston.com/news/health/articles/ 2008/11/20/state_urged_to_review_fees_to_elite_hospitals. Accessed 10 November 2010.

6. Allen S, Bombardieri M. An Unhealthy System; Part 1: A Healthcare System badly out of Balance. Available at: http://www.boston.com/news / local/articles/2008/11/16/a_healthcare_system_badly_out_of_balance. Accessed 12 November 2010.

7. McNamara E. The Patrick Administration likes the notion of universal health coverage. It just doesn't want to pay for it. Boston Magazine [Internet]. . Available at: http://www.bostonmagazine.com/articles/ universal health coverage. Accessed 10 Novemeber 2010.

8. Rosenthal MB, Frank RG, Li Z, Epstein AM. Early experience with payfor-performance. From concept to practice. JAMA. 2005;294:1788-1793.

9. Hong CS, Atlas SJ, Change Y, et al. Relationship between patient panel characteristics and primary care physician clinical performance rankings. JAMA. 2010;304:1107-1113.

10. Freund KM, Battaglia TA, Calhoun E, et al. National Cancer Institute Patient Navigation Research Program: methods, protocol, and measures. Cancer. 2008;113(12):3391-3399.

11. Freeman HP. Patient navigation: A community centered approach to reducing cancer mortality. J Cancer Educ. 2006 Spring;21(1 Suppl):S11-4.

12. Ell K, Vourlekis B, Lee PJ, Xie B. Patient navigation and case management following an abnormal mammogram: A randomized clinical trial. Prev Med. 2007;44(1):26-33.

13. Battaglia TA, Roloff K, Posner MA, Freund KM. Improving follow-up to abnormal breast cancer screening in an urban population. A patient navigation intervention. Cancer. 2007;109(2 Suppl):359-67.

14. Lasser KE, Murillo J, Medlin E, et al. A multilevel intervention to promote colorectal cancer screening among community health center patients: results of a pilot study. BMC Fam Pract. 2009;10:37.

15. Peikes D, Chen A, Schore J, Brown R. Effects of care coordination on hospitalization, quality of care, and health care expenditures among Medicare beneficiaries. JAMA. 2009;301(6):603-618.

16. Phillips CE, Rothstein JD, Beaver $\mathbf{K}$ et al. Patient navigation to increase mammography screening among inner city women. J Gen Intern Med. 2010. doi:10.1007/s11606-010-1527-2.

17. Donelan K, Mailhot JR, Dutwin D et al. patient Perspectives of clinical care and patient navigation in follow-up of abnormal mammography. J Gen Intern Med. 2010 Jul. doi:10.1007/s11606-010-1436-4. 
18. Ferrante JM, Chen PH, Kim S. The effect of patient navigation on time to diagnosis, anxiety, and satisfaction in urban minority women with abnormal mammograms: a randomized controlled trial. J Urban Health. 2008;85(1):114-24.

19. Jean-Pierre P, Fiscella $\mathbf{K}$, Freund $\mathbf{K M}$ et al. Structural and reliability analysis of a patient satisfaction with cancer-related care measure: a Multisite patient navigation research program study. Cancer. 2010 Oct 4.
20. National Accreditation Program for Breast Centers. Program standards/ components. Available at: http://accreditedbreastcenters.org/standards/ standards.html. Accessed 12 November 2010.

21. National Comprehensive Cancer Network. The case manager or patient navigator: providing support for cancer patients during treatment and beyond. Available at: http://www.nccn.com/index.php/life-with-cancer/ understanding-treatment/152-case-managers-for-cancer-patients. Accessed 12 November 2010 